Check for updates

Cite this: RSC Adv., 2019, 9, 3063

Received 17th October 2018 Accepted 10th January 2019

DOI: $10.1039 / \mathrm{c} 8 \mathrm{ra0} 0816 \mathrm{~h}$

rsc.li/rsc-advances

\section{Low-temperature catalytic hydrogenation of bio- based furfural and relevant aldehydes using cesium carbonate and hydrosiloxane $\uparrow$}

\author{
Jingxuan Long, Wenfeng Zhao, Yufei Xu, Weibo Wu, Chengjiang Fang, Hu Li (D) * \\ and Song Yang (iD *
}

Selective hydrogenation of unsaturated compounds is mainly carried out by using high-pressure hydrogen in the presence of a precious or transition metal catalyst. Here, we describe a benign approach to efficiently catalyze the hydrogenation of furfural (FUR) to furfuryl alcohol (FFA) over commercially available cesium carbonate using nontoxic and cheap polymethylhydrosiloxane (PMHS) as hydrogen source. Good to excellent FFA yields $(\geq 90 \%)$ could be obtained at $25-80{ }^{\circ} \mathrm{C}$ by appropriate control of the catalyst dosage, reaction time, and the hydride amount. FUR-to-FFA hydrogenation was clarified to follow a pseudo-first order kinetics with low apparent activation energy of $20.6 \mathrm{~kJ} \mathrm{~mol}^{-1}$. Mechanistic insights manifested that PMHS was redistributed to $\mathrm{H}_{3} \mathrm{SiMe}$, which acted as the active silane for the hydrogenation reactions. Importantly, this catalytic system was able to selectively reduce a wide range of aromatic aldehydes to the corresponding alcohols in good yields of $81-99 \%$ at $25-80{ }^{\circ} \mathrm{C}$ in $2-6 \mathrm{~h}$.

\section{Introduction}

With dwindling fossil resources, the increasing demand for energy forced the use of renewable resources as alternatives. ${ }^{1}$ Biomass is the most abundant organic carbon resource that is widely used in the production of biofuels and various platform chemicals. ${ }^{2}$ Among the value-added molecules, furfural (FUR) is able to be obtained from hemicellulose by acid-catalyzed cascade hydrolysis and dehydration, which can be further converted to a variety of chemicals and liquid fuels, ${ }^{3}$ such as 2methylfuran, 2-methyltetrahydrofuran, furfuryl alcohol (FFA), ethyl levulinate, and $\gamma$-valerolactone, through different chemical processes involving reduction as the key step. ${ }^{3,4} \mathrm{FFA}$ is particularly attractive because of its many applications in the polymer and fine chemical industries. In addition to the corrosion and solvent resistance, the resulting resin from FFA also has excellent chemical and thermal properties. ${ }^{5}$ Moreover, FFA can be used to make furan reinforced plastics due to its corrosion resistance, ${ }^{6}$ which is also an essential intermediate for the manufacture of vitamin $\mathrm{C}$, dispersants, lysine and lubricants. ${ }^{7}$

State Key Laboratory Breeding Base of Green Pesticide \& Agricultural Bioengineering, Key Laboratory of Green Pesticide \& Agricultural Bioengineering, Ministry of Education, State-Local Joint Laboratory for Comprehensive Utilization of Biomass, Center for Research \& Development of Fine Chemicals, Guizhou University, Guiyang, Guizhou 550025, China. E-mail: jhzx.msm@gmail.com; hli13@gzu.edu.cn; Fax: +86-(851)-8829-2170; Tel: +86-(851)-8829-2171

$\dagger$ Electronic supplementary information (ESI) available. See DOI: 10.1039/c8ra08616h
In the industry, copper chromite catalysts have been used to hydrogenate FUR to FFA for decades. ${ }^{8}$ The main disadvantage of this catalytic system is the toxicity of chromium oxides. ${ }^{9}$ Thus, a number of research interests have been drawn to design ecofriendly catalysts for the conversion of FUR to FFA with high activity and selectivity. ${ }^{10}$ Precious (e.g., Pd, Pt) ${ }^{11}$ and transition metals $(e . g \text {., } \mathrm{Cu}, \mathrm{Ni})^{12}$ have been explored to be efficient for catalytic hydrogenation of FUR to FFA, although they are either expensive or complicated to prepare, and the use of highpressure hydrogen gas typically requires a series of pressureresistant instruments. ${ }^{13}$ On the other hand, liquid hydrogen sources such as formic acid or alcohols (e.g., isopropanol) have received much attention in recent years. ${ }^{14}$ However, the use of formic acid as hydrogen donor may lead to the corrosion of the experimental equipment, and the alcohol can further react with the FFA by etherification to reduce the selectivity of FFA. ${ }^{15}$ Current research efforts involve the development of alternative catalytic systems that do not contain toxic species to avoid the contamination of products.

Hydrosilylation of carbonyl compounds to alcohols is one of important methods that have been widely used in academia and industry. ${ }^{16}$ This type of conversion process is very attractive because the used hydrosilanes are air- and water-stable hydride source that can be activated under mild conditions by certain catalysts or activators to form silyl ethers with carbonyl groups. ${ }^{17}$ The resulting silyl ethers can be easily converted to alcohol by additional hydrolysis. ${ }^{18}$ Among commercially available hydrosilanes, polymethylhydrosiloxane (PMHS) is a very attractive reagent of choice because it is inexpensive, commercially available, non-toxic, biodegradable, and stable to air and 
moisture. ${ }^{19}$ In addition, PMHS is of low viscosity and soluble in most organic solvents. ${ }^{20}$

Herein, selective hydrogenation of FUR to FFA was achieved over a low-cost $\mathrm{Cs}_{2} \mathrm{CO}_{3}$ using PMHS as hydride in an operationally simple manner. This catalytic strategy is more practical since $\mathrm{Cs}_{2} \mathrm{CO}_{3}$ has unique properties, such as ease to handle, low hygroscopicity, and high compatibility with organic solvents. ${ }^{21}$ The effects of different experimental parameters, like the type of catalyst and solvent, reaction temperature, reaction time, catalyst dosage, and the hydride amount on the catalytic performance were studied. In addition, the reaction kinetics and mechanism were also investigated.

\section{Experimental}

\subsection{Materials}

Furfuryl alcohol, pyridine-2-carboxaldehyde (99\%), 4-chlorobenzaldehyde (99\%), 2-nitrobenzaldehyde (99\%), methanol (99\%), 5-methylfurfural (99\%), 2-methylthiazole-5carbaldehyde (99\%), salicylaldehyde (99\%), 1-naphthaldehyde (99\%), furfural, phenylsilane (97\%), polymethylhydrosiloxane (PMHS, 99\%), triethoxysilane (97\%), diphenylsilane (97\%), deuterated dimethyl sulfoxide (DMSO- $d_{6}, 99.8$ atom\% D), 1,4dioxane (99\%), potassium carbonate $\left(\mathrm{K}_{2} \mathrm{CO}_{3}, 99 \%\right)$, cesium carbonate $\left(\mathrm{Cs}_{2} \mathrm{CO}_{3}, 99 \%\right)$, naphthalene (99\%), methanol ( $\mathrm{MeOH}, 99 \%)$, triethylsilane (99\%), trimethoxysilane (99\%) and 1,1,3,3-tetramethyldisiloxane (97\%) were purchased from Beijing Innochem Technology Co., Ltd. Tetrahydrofuran (THF, 99\%)and 1,1,1,3,5,5,5-heptamethyltrisiloxane (98\%) were purchased from TCI (Shanghai) Development Co., Ltd. Lithium carbonate $\left(\mathrm{Li}_{2} \mathrm{CO}_{3}, 99 \%\right)$, calcium carbonate $\left(\mathrm{CaCO}_{3}, 98 \%\right)$, cesium sulfate $\left(\mathrm{Cs}_{2} \mathrm{SO}_{4}, 98 \%\right)$ and sodium carbonate $\left(\mathrm{Na}_{2} \mathrm{CO}_{3}\right.$, 99\%) were purchased from Shanghai Aladdin Industrial Inc. Cesium bicarbonate $\left(\mathrm{CsHCO}_{3}, 99 \%\right)$, cesium chloride $(\mathrm{CsCl}$, 98\%), acetonitrile (MeCN, 99\%), 5-methyltetrahydrofuran (MTHF, 99\%), dichloromethane (DCM, 99\%), dimethyl sulfoxide (DMSO, 99\%) and N,N-dimethylformamide (DMF, 99\%) were purchased from Sigma-Aldrich Co. LLC. Other used reagents were of analytical grade without further purification, unless stated otherwise.

\subsection{Procedures for catalytic hydrogenation of FUR to FFA}

All the reactions were carried out in $15 \mathrm{~mL}$ Ace pressure tubes. In a typical procedure, $0.5 \mathrm{mmol}$ FUR, $0.05 \mathrm{mmol} \mathrm{Cs}_{2} \mathrm{CO}_{3}(16$ $\mathrm{mg}$ ), $2.0 \mathrm{~mL}$ DMF and $0.1 \mathrm{~g}$ PMHS were added into the tube and sealed. Then, the mixture was transferred into an oil-bath and magnetically stirred at $400 \mathrm{rpm}$ for a specific reaction time. The zero time was established as the tube was placed into the oil bath preheated to $25-80{ }^{\circ} \mathrm{C}$. After the reaction was completed and cooled down to room temperature, $3 \mathrm{~mL}$ methanol was added into the reaction system, followed by stirring under ambient conditions for $30 \mathrm{~min}$ for alcoholysis of siloxane intermediate. The reaction solution was filtered to remove solid particles, followed by quantitative analysis with gas chromatography (GC) and gas chromatography-mass spectrometry (GCMS).

\subsection{Analytical method}

The FFA yield and FUR conversion were quantitatively analyzed by GC (Agilent 7890B) with a HP-5 column $(30 \mathrm{~m} \times 0.320 \mathrm{~mm} \times$ $0.25 \mu \mathrm{m})$ and a flame ionization detector. Naphthalene $(10 \mathrm{mg})$ was utilized as internal standard by referring to the standard curves (with $R^{2}>0.9998$ ) made from commercial samples. Liquid products were identified by GC-MS (Agilent 6890N GC/ 5973 MS, Santa Clara, CA). The substrate conversion rate $(C, \mathrm{~mol} \%)$ and product yield $(Y, \mathrm{~mol} \%)$ were calculated by following below equations:

$$
\begin{aligned}
C(\%)= & {\left[1-\frac{\text { mole concentration of substrate in product }}{\text { mole concentration of initial substrate }}\right] } \\
& \times 100 \%
\end{aligned}
$$

$$
Y(\%)=\left[\frac{\text { mole concentration of product }}{\text { mole concentration of initial substrate }}\right] \times 100 \%
$$

\subsection{Catalyst recycling study}

After each cycle of reactions, the remaining catalyst was separated by centrifugation, washing with DMF and acetone for 4 times, respectively, followed by drying at $80{ }^{\circ} \mathrm{C}$ in the atmosphere of $\mathrm{N}_{2}$ for $8 \mathrm{~h}$, which was then directly used for the next run. STEM (scanning transmission electron microscopy) test of the recovered $\mathrm{Cs}_{2} \mathrm{CO}_{3}$ was measured by JEOL 2100 TEM/STEM.

\section{Results and discussion}

\subsection{Effect of different catalysts}

Initially, different catalysts were screened for hydrogenation of FUR to FFA using PMHS as $\mathrm{H}$-donor at room temperature in DMF. $\mathrm{Cs}_{2} \mathrm{CO}_{3}$ was found to show the highest activity, being capable of converting FUR to FFA with $45.5 \%$ yield, $55.0 \%$ conversion and TOF of $5.6 \mathrm{~h}^{-1}$ at room temperature for $1 \mathrm{~h}$ (Table 1 , entry 1 ). In contrast, nearly no reaction took place by using $\mathrm{Li}_{2} \mathrm{CO}_{3}, \mathrm{Cs}_{2} \mathrm{SO}_{4}$, CsCl or $\mathrm{CaCO}_{3}$ as catalyst (entries 2-5). When considering the influence of cations, $\mathrm{Cs}_{2} \mathrm{CO}_{3}, \mathrm{Na}_{2} \mathrm{CO}_{3}$ and $\mathrm{K}_{2} \mathrm{CO}_{3}$ were more active in the reaction than other

Table 1 The conversion of FUR to FFA over difference catalysts ${ }^{a}$

\begin{tabular}{lllll}
\hline Entry & Cat. & $\begin{array}{l}\text { Yield } \\
(\%)\end{array}$ & $\begin{array}{l}\text { Conversion } \\
(\%)\end{array}$ & $\mathrm{TOF}^{b}\left(\mathrm{~h}^{-1}\right)$ \\
\hline 1 & $\mathrm{Cs}_{2} \mathrm{CO}_{3}$ & 45.5 & 55.0 & 5.6 \\
2 & $\mathrm{Li}_{2} \mathrm{CO}_{3}$ & 0 & 0 & 0 \\
3 & $\mathrm{Cs}_{2} \mathrm{SO}_{4}$ & 0 & 0 & 0 \\
4 & $\mathrm{CsCl}_{5}$ & 0 & 0 & 0 \\
5 & $\mathrm{CaCO}_{3}$ & 0 & 0 & 0 \\
6 & $\mathrm{~K}_{2} \mathrm{CO}_{3}$ & 29.5 & 32.4 & 1.4 \\
7 & $\mathrm{Na}_{2} \mathrm{CO}_{3}$ & 18.5 & 22.4 & 0.7
\end{tabular}

${ }^{a}$ Reaction condition: $0.5 \mathrm{mmol}$ FUR, $16 \mathrm{mg}$ catalyst, PMHS $(1.47 \mathrm{mmol}$ $\mathrm{H}^{-}$), $2 \mathrm{~mL} \mathrm{DMF}, 25{ }^{\circ} \mathrm{C}$, and $1 \mathrm{~h} .{ }^{b}$ Turnover frequency (TOF) was evaluated on the basis of (mole of FUR)/(mole of the catalyst $\times$ reaction time). 
carbonate bases (entries 1, 6 and 7), indicating that the size of the cation played an important role in the reaction. With the increase of the radius of the cation, the ionic property of the salt increased, thus with enhanced solubility. ${ }^{20 b}$ Among the ions of alkali and alkaline earth metals, $\mathrm{Cs}^{+}$has the largest ionic radius and the weakest polarization, which allows the paired carbonate ion to be more freely available to interact with the hydrosilane. In addition to the cation, the effect of the anion on the reaction is not negligible, mainly related to its basicity that has a positive correlation with nucleophilic ability. In this regard, compared with chloridion (entry 4), carbonate with relatively higher nucleophilic ability is more prone to attack PMHS, thus activating the silane to release hydride. ${ }^{20 b}$ In view of the superior FFA yield, $\mathrm{Cs}_{2} \mathrm{CO}_{3}$ was selected as the optimal catalyst for the reaction.

\subsection{Effect of reaction temperature and time}

In the presence of $\mathrm{Cs}_{2} \mathrm{CO}_{3}$, the effect of reaction temperature and time on the hydrogenation of FUR to FFA was studied. All experiments were conducted at 25,60 , and $80{ }^{\circ} \mathrm{C}$ with the reaction time in the range of 0.5 to $8 \mathrm{~h}$, and the results are displayed in Fig. 1. Both FFA yield and FUR conversion increased with the extension of reaction time from 0.5 to $6 \mathrm{~h}$,
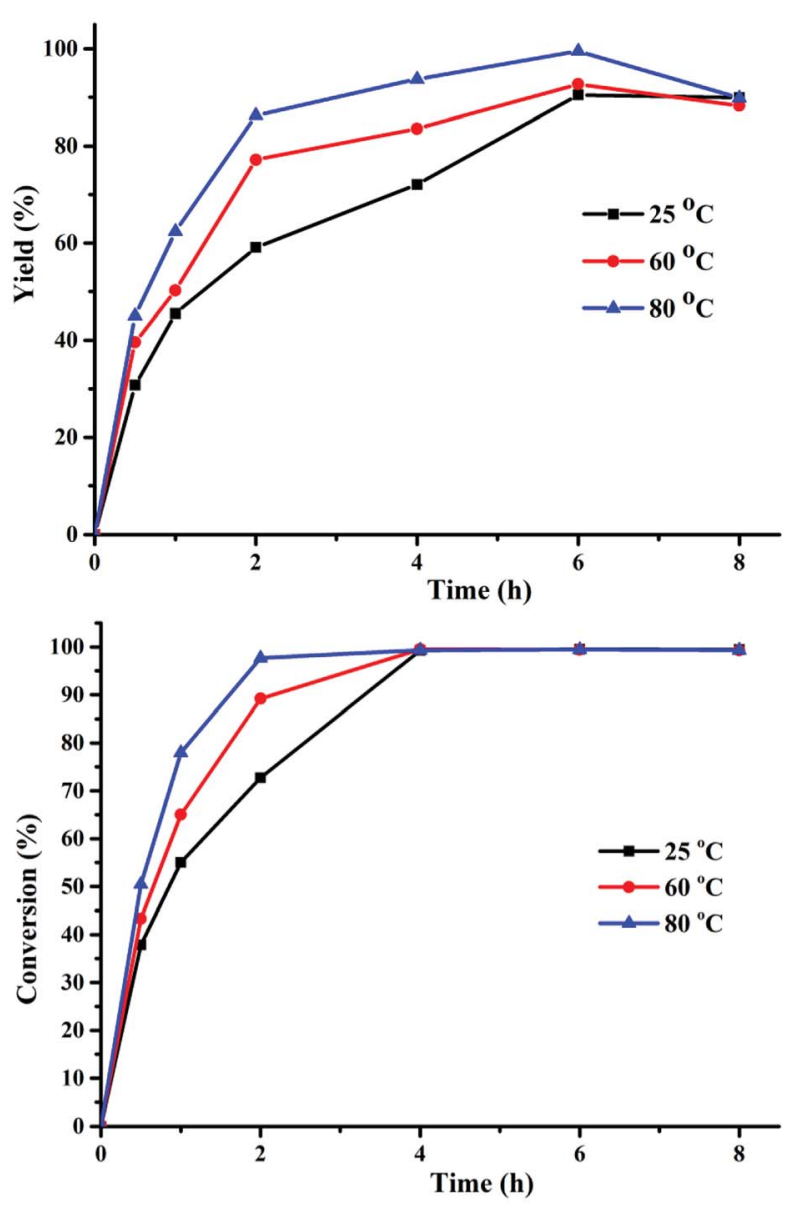

Fig. 1 The effect of reaction time and temperature on the synthesis of

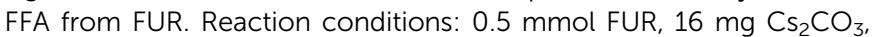
PMHS (1.47 $\left.\mathrm{mmol} \mathrm{H}^{-}\right), 2 \mathrm{~mL}$ DMF. displaying that a relatively longer reaction time could promote the FFA formation. However, the FFA selectivity decreased as the reaction time was prolonged to $8 \mathrm{~h}$ due to the generation of siloxane intermediate (Fig. S1-S3†). Therefore, $6 \mathrm{~h}$ was chosen as the optimum reaction time. It was obvious that the reaction efficiency was enhanced as reaction temperature increased from 25 to $80{ }^{\circ} \mathrm{C}$ in $6 \mathrm{~h}$. Remarkably, when raising the temperature to $80{ }^{\circ} \mathrm{C}$, the FA yield could reach $99 \%$. Therefore, the optimal temperature of $80^{\circ} \mathrm{C}$ and time of $6 \mathrm{~h}$ were beneficial to obtain FFA with less intermediates and byproducts being formed.

\subsection{Effect of different solvents}

The effect of the used solvents in this chemoselective hydrosilylation reaction was then examined over $\mathrm{Cs}_{2} \mathrm{CO}_{3}$. On the one hand, solvent polarity could affect the solvent-reactant interactions. $^{22}$ As the polarity of the solvent increases, the increased interaction of FUR-solvent may promote the formation of FFA. On the other hand, with the increase of the solvent polarity, the solubility of PMHS into the solvent can also be enhanced, thereby facilitating the interaction of PMHS with the catalyst to release $\mathrm{H}^{-}$. Further interaction of hydride with FUR gives FFA. Highly polar aprotic solvent such as DMF and DMSO displayed high FUR conversion of $99 \%$ and satisfactory FFA yield of $99 \%$ (Fig. 2). In contrast, the solvents (e.g., THF, DCM, MTHF, $\mathrm{CH}_{3} \mathrm{CN}$, 1,4-dioxane) with relatively low polarity exhibited inferior performance with FFA yield of $82 \%, 70 \%, 65 \%, 64 \%$, and $8.2 \%$, respectively. Notably, methanol and water were inactive for the reaction, due to the occurrence of dehydrogenative silylation between PMHS and the protic solvent (Fig. S10†) to release $\mathrm{H}_{2}$ (ref. 23) that cannot be used as active hydrogen source over $\mathrm{Cs}_{2} \mathrm{CO}_{3}$.

\subsection{Effect of different hydrosilanes}

The influence of various hydrosilanes on the hydrogenation of FUR to FFA was studied by using $\mathrm{Cs}_{2} \mathrm{CO}_{3}$ as catalyst (Table 2).

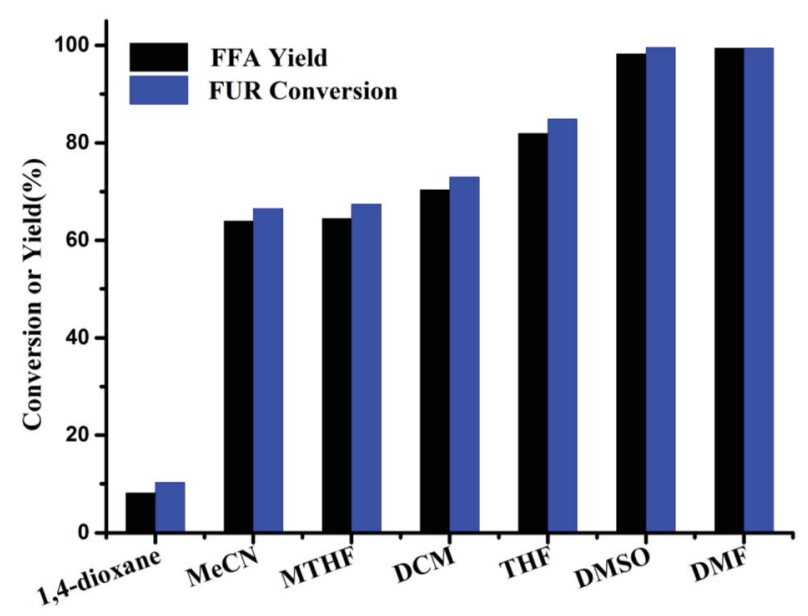

Fig. 2 Effect of solvents on the synthesis of FFA from FUR. Reaction conditions: $0.5 \mathrm{mmol} F U R, 16 \mathrm{mg} \mathrm{Cs} \mathrm{CO}_{3}$, PMHS $\left(1.47 \mathrm{mmol} \mathrm{H}^{-}\right), 2 \mathrm{~mL}$ solvent, $80^{\circ} \mathrm{C}$, and $6 \mathrm{~h}$. 
Table 2 Reaction rate constant $k$ at different temperatures

\begin{tabular}{lll}
\hline $\begin{array}{l}\text { Temperature } \\
(\mathrm{K})\end{array}$ & $\begin{array}{l}\text { Reaction rate } \\
\text { constant, } k(1 / \mathrm{min})\end{array}$ & $\begin{array}{l}\text { Coefficient of } \\
\text { determination }\left(R^{2}\right)\end{array}$ \\
\hline 398 & 0.0141 & 0.9685 \\
333 & 0.0184 & 0.9474 \\
353 & 0.0214 & 0.9537
\end{tabular}

Among the employed simple silanes, phenylsilane and diphenylsilane (Table $\mathrm{S} 1, \uparrow$ entries 6 and 7) revealed relatively higher yields of FFA, which might be due to their relatively poor stability of silicon atoms. ${ }^{24}$ However, they are usually too dear to be used on a large scale. ${ }^{25}$ To our astonishment, both the conversion of FUR and the yield of FFA were relatively high (>99\%) when using cheap PMHS as the hydrogen source (Table $\mathrm{S} 1, \dagger$ entries 8). Besides, the polymerized PMHS was easy to form resins to encapsulate the catalyst, ${ }^{26}$ which would be helpful for the separation of the catalyst from the reaction mixture. From the economic and eco-friendly points of view, PMHS was screened out as the optimal hydrogen source for FUR hydrogenation.

\subsection{Effect of PMHS dosage}

The PMHS dosage was found to have a significant effect on FFA synthesis, as shown in Fig. 3. As the PMHS dosage increased from 0.04 to $0.1 \mathrm{~g}$, the FFA yield increased from 30 to $99 \%$ accordingly. Nevertheless, when the PMHS dosage was more than $0.1 \mathrm{~g}$, the FFA yield was decreased despite of constant FUR conversion. The reduction of FFA yield was likely to be the encapsulation of $\mathrm{Cs}_{2} \mathrm{CO}_{3}$ by the resins derived from $\mathrm{PMHS}^{26}$ that impeded the contact of FUR to the active sites (carbonate). Therefore, the maximum FFA yield could be acquired by utilizing $0.1 \mathrm{~g}$ PMHS at $80{ }^{\circ} \mathrm{C}$ for $6 \mathrm{~h}$ in DMF.

\subsection{Effect of catalyst dosage}

The effect of catalyst dosage on the hydrogenation of FUR to FFA under the optimal reaction conditions was further investigated,

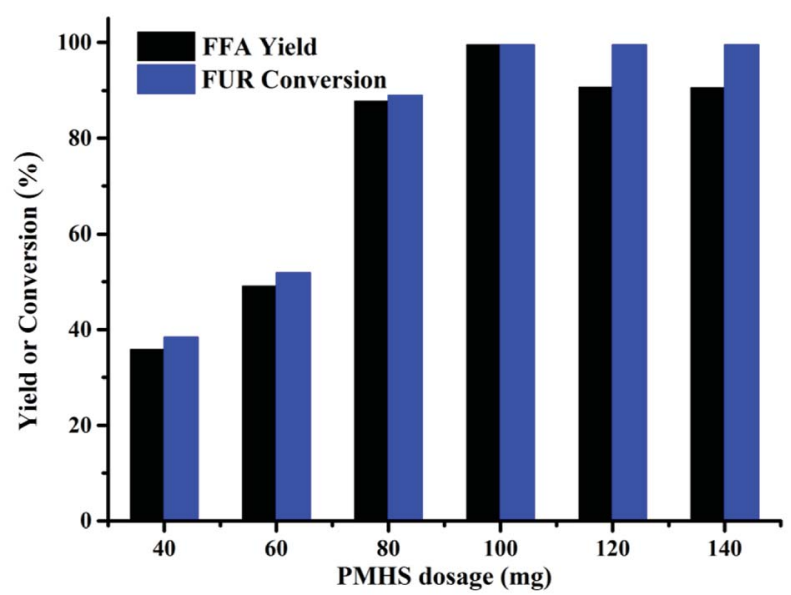

Fig. 3 Effect of PMHS dosage on the synthesis of FFA from FUR. Reaction conditions: $0.5 \mathrm{mmol} F U R, 16 \mathrm{mg} \mathrm{Cs}_{2} \mathrm{CO}_{3}, 2 \mathrm{~mL} \mathrm{DMF}, 80^{\circ} \mathrm{C}$, and $6 \mathrm{~h}$. and the results are shown in the Fig. 4. 99\% FUR conversion and $99 \%$ FFA yield were obtained in the presence of $16 \mathrm{mg} \mathrm{Cs}_{2} \mathrm{CO}_{3}$ at $80{ }^{\circ} \mathrm{C}$ for $6 \mathrm{~h}$. When the $\mathrm{Cs}_{2} \mathrm{CO}_{3}$ dosage increased from 0 to $16 \mathrm{mg}$, both FUR conversion and FFA yield increased to $99 \%$. However, when the catalyst dosage was beyond $16 \mathrm{mg}$, the yield of FFA displayed a markedly reduction ascribed to the adsorption of FFA onto the surface of the superfluous $\mathrm{Cs}_{2} \mathrm{CO}_{3}$ solid, or to the physical adsorption of water, thus inhibiting the alcoholysis of the siloxane intermediate to release the product. ${ }^{27}$ In addition, the fast ineffective depletion of PMHS was most possible to occur by forming pentavalent silicate species $\left(\mathrm{H}_{3} \mathrm{Si}(\mathrm{Me})-\mathrm{CO}_{3}\right)$ with carbonate. ${ }^{28}$ Although the pentavalent silicate species were active for the reduction of carbonyl compounds, ${ }^{29}$ serious polymerization was to exist when utilizing superfluous $\mathrm{Cs}_{2} \mathrm{CO}_{3}$ (e.g., $18 \mathrm{mg}$ ), which hence might decrease the catalyst activity.

\subsection{Catalyst recycling study}

Recyclability study for FFA producing from FUR was conducted over $\mathrm{Cs}_{2} \mathrm{CO}_{3}$ at $25{ }^{\circ} \mathrm{C}$ and $80{ }^{\circ} \mathrm{C}$ for $6 \mathrm{~h}$ in presence of $\mathrm{Cs}_{2} \mathrm{CO}_{3}(16$ $\mathrm{mg}$ ), while the catalyst was recycled with decline in FFA yield (Table $\mathrm{S} 2 \dagger)$. STEM image showed the distribution of the evenly dispersed elements, such as $\mathrm{Cs}, \mathrm{Si}, \mathrm{C}$ and O-species of recycled $\mathrm{Cs}_{2} \mathrm{CO}_{3}$ (Fig. S4 $\dagger$ ). From the above data, it was speculated that the reduced catalytic activity could be attributed to interaction of cesium carbonate with hydrosilane. To verify this point, a nuclear magnetic verification experiment was carried out to react cesium carbonate with $\mathrm{PhSiH}_{3}$ and PMHS under the reaction conditions of $25{ }^{\circ} \mathrm{C}, 6 \mathrm{~h}$ in the presence of DMSO- $d_{6}$. NMR studies (as represented in Fig. S5 $\dagger$ ) disclosed the formation of silicon formate, which could be converted to value-added chemical - formic acid by hydrolysis. ${ }^{30}$ Considering the low-cost of $\mathrm{Cs}_{2} \mathrm{CO}_{3}$, it would be still promising to co-upgrade carbonate during the reduction process.

\subsection{Kinetic study of FUR-to-FFA conversion}

To investigate the reaction kinetics of FUR being converted to FFA, the reaction rate constants at various temperatures were

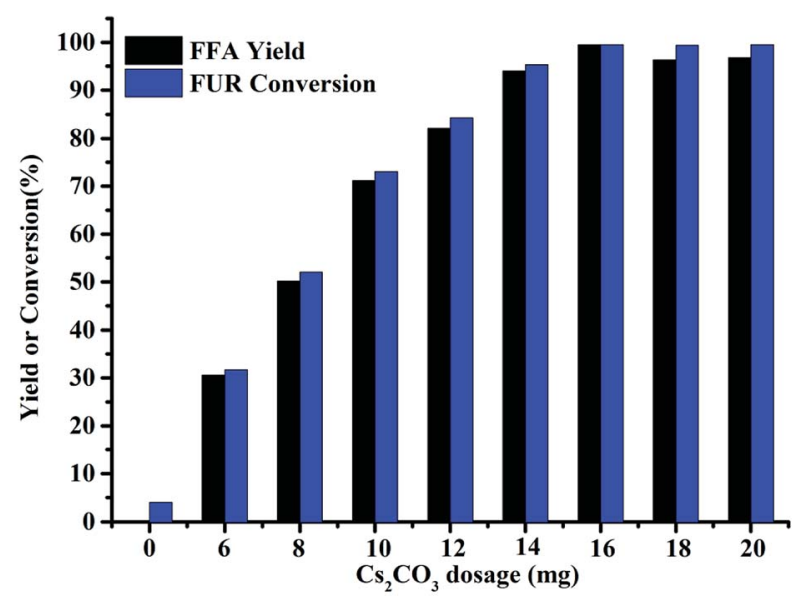

Fig. 4 Effect of catalyst dosage on the synthesis of FFA from FUR. Reaction conditions: $0.5 \mathrm{mmol} F U R$, PMHS $\left(1.47 \mathrm{mmol} \mathrm{H}^{-}\right), 2 \mathrm{~mL}$ DMF, $80^{\circ} \mathrm{C}$, and $6 \mathrm{~h}$. 
determined based on the increased amount of FFA as a function of time (Table 2). It was assumed that the hydrogenation of FUR obeyed first-order kinetics. ${ }^{31}$ The reaction rate constant $(k)$ was determined by using below equations.

$$
\frac{\mathrm{d}[\mathrm{FA}]}{\mathrm{d} t}=k[\mathrm{FAL}]=\mathrm{d}[\mathrm{FAL}] / \mathrm{d} t
$$
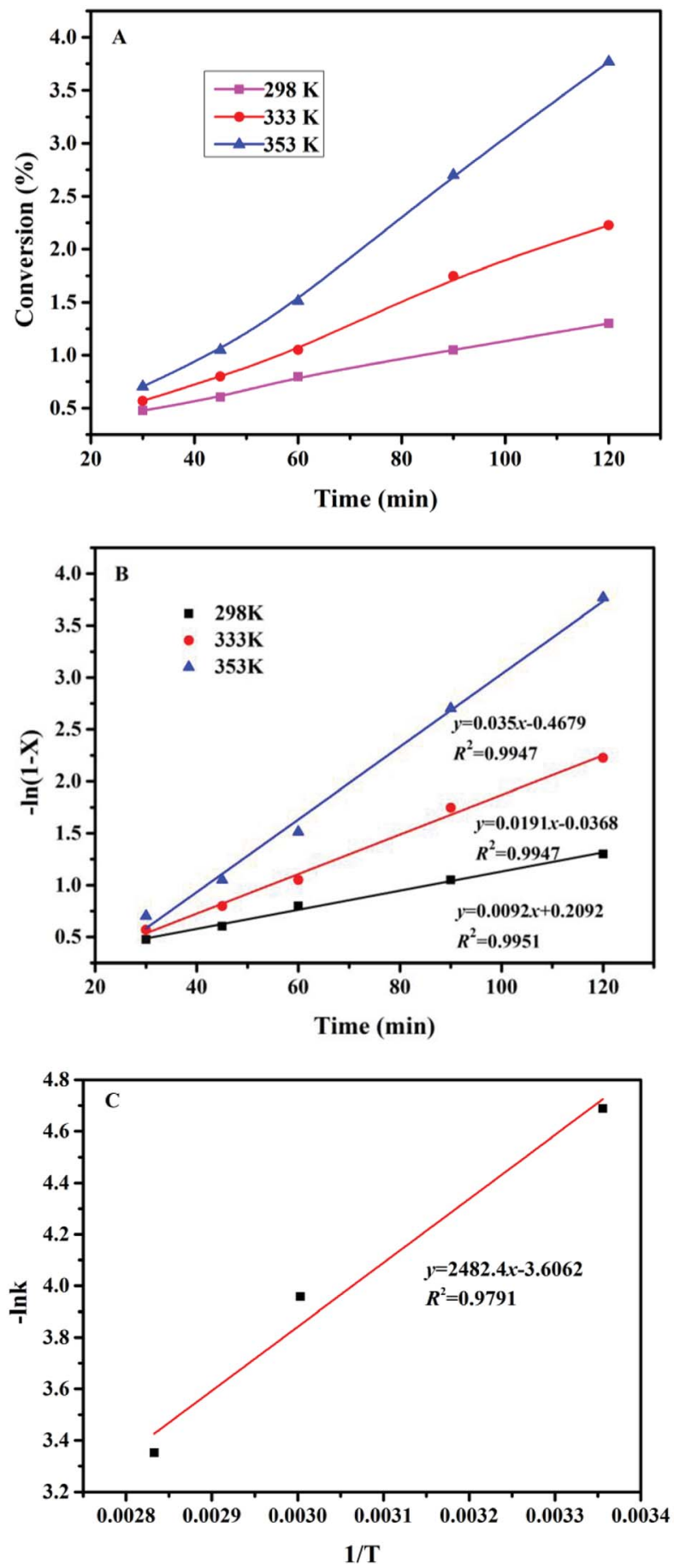

Fig. 5 (A) Kinetic curves of $\mathrm{Cs}_{2} \mathrm{CO}_{3}$ for the hydrogenation of FUR to FFA; (B) linear relationship between time and $-\ln (1-X)$ at different reaction temperatures catalyzed by $\mathrm{Cs}_{2} \mathrm{CO}_{3}$; (C) Arrhenius plot of $-\ln \mathrm{k}$ vs. $1 / T$ catalyzed by $\mathrm{Cs}_{2} \mathrm{CO}_{3}$.

$$
\begin{aligned}
& -\ln (1-X)=k t+c \\
& \ln k=-\frac{E_{\mathrm{a}}}{R T}+\ln A
\end{aligned}
$$

where $X$ denotes the FUR conversion, the $-\ln (1-X)$ versus the reaction time was fitted at different temperatures in Fig. 5, confirming that the reaction followed the pseudo-first order kinetics for all temperatures studied and the rate constants calculated were $0.0092,0.0191$, and $0.0350 \mathrm{~min}^{-1}$ at reaction temperatures of 298,333 , and $353 \mathrm{~K}$, respectively. The apparent activation energy $\left(E_{\mathrm{a}}\right)$ of $20.6 \mathrm{~kJ} \mathrm{~mol}^{-1}$ was determined by the numerical regression assuming valid Arrhenius equation (as shown in eqn (2)), which was much lower than those of previously reported catalysts in the conversion of FUR to FFA (Table 3). Vaidya and Mahajani, using a noble metal-based catalyst (Pt/C) and 2-propanol as solvent, reported a value equal to $28 \mathrm{~kJ} \mathrm{~mol}^{-1}$, which is a low value considering that the absence of diffusional resistances was verified..$^{32}$ Sharma et al. reported that $\mathrm{Cu}: \mathrm{Zn}: \mathrm{Cr}: \mathrm{Zr}$ based catalysts for the hydrogenation of FUR to FFA, with apparent activation energy of $102 \mathrm{~kJ} \mathrm{~mol}^{-1} \cdot{ }^{31}$ Potentially, the final disposal of the metal catalysts might cause serious environmental pollution. ${ }^{36}$ In this regard, our developed catalytic system meets the economic and eco-friendly design concept.

Thermodynamic characteristics of the reaction were also studied based on the results of the kinetic studies. For this purpose, the Eyring-Polanyi equation was used.

Table 3 Kinetic parameters of $\mathrm{Cs}_{2} \mathrm{CO}_{3}$ and previously reported catalysts for the hydrogenation of FUR to FFA

\begin{tabular}{lll}
\hline Catalyst & $\begin{array}{l}\text { Activation energy } \\
\left(\mathrm{kJ} \mathrm{mol}^{-1}\right)\end{array}$ & References \\
\hline $\mathrm{CuMgAl}$ & 127 & 35 \\
$\mathrm{Cu}: \mathrm{Zn}: \mathrm{Cr}: \mathrm{Zr}$ & 102 & 31 \\
$\mathrm{Au} / \mathrm{Al}_{2} \mathrm{O}_{3}$ & 45.0 & 34 \\
$\mathrm{Co}-\mathrm{Cu} / \mathrm{SBA}-15$ & 38.5 & 33 \\
$\mathrm{Pt} / \mathrm{C}$ & 28.0 & 32 \\
$\mathrm{Cs}_{2} \mathrm{CO}_{3}$ & 20.6 & This work
\end{tabular}

${ }^{a}$ Reaction conditions: $0.05 \mathrm{mmol}$ FUR, $16 \mathrm{mg} \mathrm{Cs}_{2} \mathrm{CO}_{3}, 2 \mathrm{~mL}$ DMF, PMHS (1.47 $\left.\mathrm{mmol} \mathrm{H}^{-}\right)$.

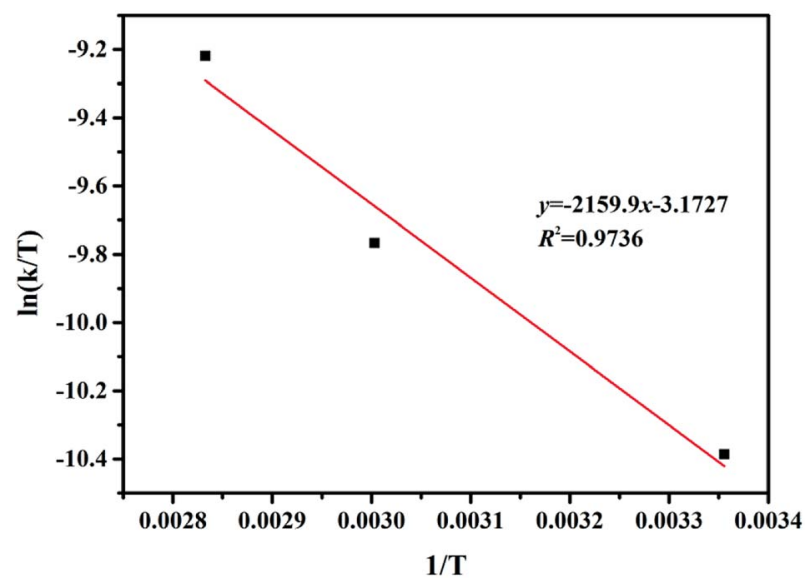

Fig. 6 Eyring-Polanyi plot between $\ln (k / T)$ and $1 / T$. 


$$
\begin{gathered}
\ln \left(\frac{k}{T}\right)=-\frac{\Delta H}{R T}+\ln \left(\frac{k_{\mathrm{b}}}{h}\right)+\frac{\Delta S}{R} \\
\Delta G=\Delta H-T \Delta S
\end{gathered}
$$

Table 4 Thermodynamic parameters of the reaction system

\begin{tabular}{llllll}
\hline & $\Delta H$ & $\Delta S$ & \multicolumn{4}{l}{$\Delta G\left(\mathrm{~kJ} \mathrm{~mol}^{-1}\right)$} & \\
\cline { 4 - 6 } Parameters & $\begin{array}{l}\Delta H \\
\left(\mathrm{~kJ} \mathrm{~mol}^{-1}\right)\end{array}$ & $\begin{array}{l}\Delta S \\
\left(\mathrm{~kJ} \mathrm{~mol}^{-1} \mathrm{~K}^{-1}\right)\end{array}$ & $298 \mathrm{~K}$ & $333 \mathrm{~K}$ & $353 \mathrm{~K}$ \\
\hline Values & 18.0 & -0.223 & 84.5 & 92.3 & 96.7
\end{tabular}

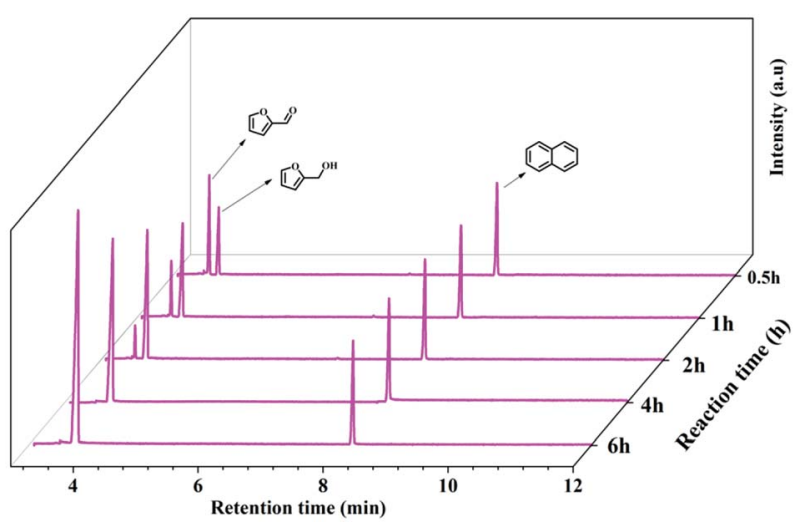

Fig. 7 GC spectrum at different reaction times for the conversion of FUR to FFA. Reaction condition: $0.5 \mathrm{mmol} F U R, 16 \mathrm{mg} \mathrm{Cs}_{2} \mathrm{CO}_{3}, \mathrm{PMHS}$ (1.47 $\mathrm{mmol} \mathrm{H}{ }^{-}$), $2 \mathrm{~mL} \mathrm{DMF,} 25^{\circ} \mathrm{C}$. $k$ is the rate constant of temperature $T . \Delta H$ and $\Delta S$ are the changes of the enthalpy and entropy in the reaction system, respectively. $k_{\mathrm{b}}, h$ and $R$ are the Boltzmann, Planck, and gas constants, respectively. ${ }^{37} \Delta H$ and $\Delta S$ were calculated from the slope and intercept of the Eyring-Polanyi plot for the reaction (Fig. 6). The eqn (3) can model the varies in the Gibbs free energy $(\Delta G)$ at temperature $T$. The values of $\Delta H, \Delta S$ and $\Delta G$ for the reaction are shown in Table 4 . The positive values of $\Delta H$ displayed that the hydrogenation of FUR to FFA catalyzed by cesium carbonate is an endothermic reaction, which can be carried out under heating conditions. The negative value of $\Delta S$ displayed that the degree of ordered geometry/alignment of the reactants in the ground state was lower than transient state. The positive value of $\Delta G$ displayed that this reaction was essentially non-spontaneous.

\subsection{Reaction pathway for FUR-to-FFA hydrogenation and substrate scope expansion}

To definitely illuminate the reaction pathway for converting FUR to FFA, the GC spectra were conducted at $25{ }^{\circ} \mathrm{C}$ by changing the reaction time from 0.5 to $6 \mathrm{~h}$ (Fig. 7), clearly indicating that the content of FUR was decreased, and the content of FFA increased by prolonging the reaction time. The mechanism of hydrogenation of aldehydes and ketones catalyzed by $\mathrm{Cs}_{2} \mathrm{CO}_{3}$ is very similar to the reduction process of amides. ${ }^{38}$ The interaction of PMHS with carbonate dianion is likely to produce high valency silicate intermediates (Fig. S6 and $\mathrm{S} 7 \dagger$ ), which can transfer hydrides to carbonyl groups. During our experiments, a large amount of gas, methyl silane $\left(\mathrm{H}_{3} \mathrm{SiMe}\right)$, was observed immediately after the PMHS was added to the DMF solution of $\mathrm{Cs}_{2} \mathrm{CO}_{3}$ mixed with the

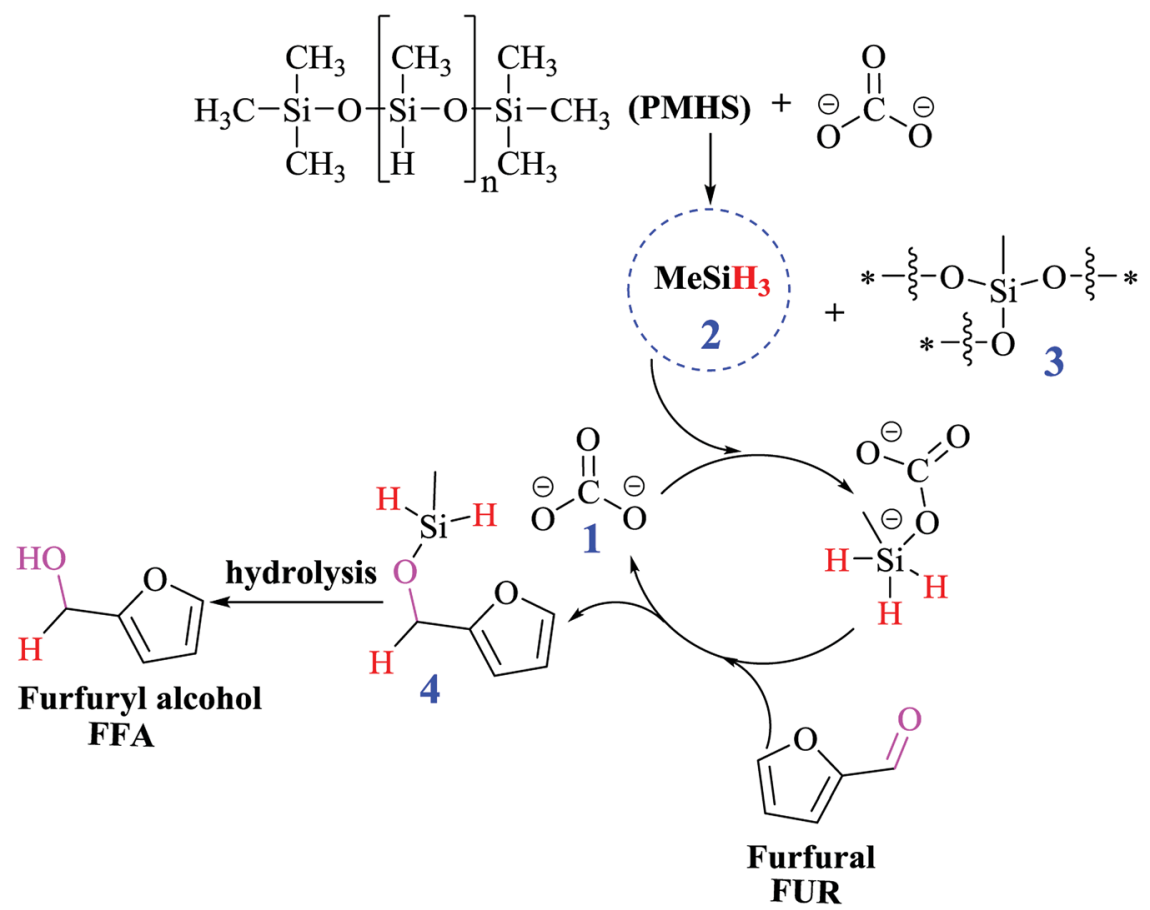

Scheme 1 Proposed reaction pathway for the conversion of FUR to FFA. 
Table 5 Catalytic hydrogenation of different aldehydes to alcohols with $\mathrm{Cs}_{2} \mathrm{CO}_{3}$ and $\mathrm{PMHS}^{a}$

\begin{tabular}{|c|c|c|c|c|c|}
\hline Entry & Substrate & Product & Temp. $\left({ }^{\circ} \mathrm{C}\right)$ & Time (h) & Yield (\%) \\
\hline 1 & & & 80 & 6 & 85 \\
\hline 2 & & & 80 & 6 & $>99$ \\
\hline 3 & & & 25 & 2 & $>99$ \\
\hline 4 & & & 80 & 6 & 88 \\
\hline 5 & & & 80 & 6 & 87 \\
\hline 6 & & & 80 & 6 & 81 \\
\hline 7 & & & 80 & 6 & $>99$ \\
\hline
\end{tabular}

substrate, which is consistent with previous studies. ${ }^{39}$ In order to verify the presence of methylsilane, PMHS was directly added into the solution of DMSO- $d_{6}$ and $\mathrm{Cs}_{2} \mathrm{CO}_{3}$. Nuclear magnetic detection of the reaction mixture was performed after $6 \mathrm{~h}$ at room temperature (Fig. S8 $\dagger$ ). Two quartet peaks were observed at $\delta=3.4$ and $0.19 \mathrm{ppm}$ in ${ }^{1} \mathrm{H}$ NMR spectra, respectively, indicating the formation of $\mathrm{MeSiH}_{3}$ during the reaction process.

Based on the empirical evidences, the possible reaction mechanism of the hydrogenation of FUR to FFA is shown in Scheme 1. In the presence of Lewis base (carbonate 1), PMHS was first cracked to form small silane $\left(\mathrm{H}_{3} \mathrm{SiMe} 2\right)$, and a series of siloxanes 3. The resulting $\mathrm{H}_{3} \mathrm{SiMe}$ would form a pentavalent silicate with carbonate (Fig. S6 $\dagger$ ), followed by reacting with the carbonyl group in FUR to form hexavalent (Fig. S7 $\dagger$ ), which is a nucleophile in nature ${ }^{40}$ and can activate aldehyde group by hydride transfer. The release of carbonate 1 to the next catalytic cycle affords silyl ether $\mathbf{4}$, followed by the hydrolysis of the siloxane intermediate to give FFA.

In order to examine the scope of this catalytic system for hydrogenation of FUR to FFA with $\mathrm{Cs}_{2} \mathrm{CO}_{3}$ using PMHS as $\mathrm{H}$ donor, different aromatic aldehydes were employed as substrates, and the results are shown in Table 5. The hydrogenation of various aldehydes to corresponding alcohols, as identified by GC-MS (Fig. S9†), could achieved high yields 81$99 \%$ under mild reaction conditions. In particular, nitro- and chlorine-groups were tolerated during the reducing process (Table 5, entries 4 and 5).

\section{Conclusions}

In summary, an efficient and benign catalytic protocol was developed for selective reduction of FUR to FFA in yields of up to $99 \%$ over $\mathrm{Cs}_{2} \mathrm{CO}_{3}$ by using eco-friendly and inexpensive PMHS as H-donor. This developed reaction system followed a pseudo-first order reaction with apparent activation energy of $20.6 \mathrm{~kJ} \mathrm{~mol}^{-1}$, which was much lower than previously reported ones. The mechanistic study illustrated the reaction proceeding via the hydrosilylation process with $\mathrm{H}_{3}$ SiMe as the key hydride species formed by the activation of PMHS with carbonate, as clarified by ${ }^{1} \mathrm{H}$ NMR. Moreover, this catalytic strategy was also appropriate for selective hydrogenation of different aromatic aldehydes to corresponding alcohols in good yields.

\section{Conflicts of interest}

There are no conflicts to declare. 


\section{Acknowledgements}

This work was supported by the financial support of the National Natural Science Foundation of China (21576059 \& 21666008), Key Technologies R\&D Program of China (2014BAD23B01), Fok Ying-Tong Education Foundation (161030), and Guizhou Science \& Technology Foundation ([2018]1037 \& [2017]5788).

\section{References}

1 X. Li, P. Jia and T. Wang, ACS Catal., 2016, 6, 7621-7640.

2 (a) B. Liu and Z. Zhang, ACS Catal., 2015, 6, 326-338; (b) H. Li, A. Riisager, S. Saravanamurugan, A. Pandey, R. S. Sangwan, S. Yang and R. Luque, ACS Catal., 2018, 8, 148-187; (c) J. X. Long, W. F. Zhao, Y. F. Xu, H. Li and S. Yong, Catalysts, 2018, 8, 633; (d) H. Li, W. F. Zhao, W. Dai, J. X. Long, M. Watanabe, S. Meier, S. Saravanamurugan, S. Yang and A. Riisager, Green Chem., 2018, 20, 5327-5335; (e) H. Li, Z. Fang, J. Luo and S. Yang, Appl. Catal., B, 2017, 200, 182-191.

3 G. Li, W. Jiao, Z. Sun, Y. Zhao, Z. Shi, Y. Yan and Y. Tang, ACS Sustainable Chem. Eng., 2018, 6, 4316-4320.

4 (a) H. Wang, X. Li, X. Lan and T. Wang, ACS Catal., 2018, 8, 2121-2128; (b) D. Vargas-Hernández, J. M. Rubio-Caballero, J. Santamaría-González, R. Moreno-Tost, J. M. MeridaRobles, M. A. Perez-Cruz and P. Maireles-Torres, J. Mol. Catal. A: Chem., 2014, 383, 106-113; (c) H. Li, W. Zhao, S. Saravanamurugan, W. Dai, J. He, S. Meier, S. Yang and A. Riisager, Communications Chemistry, 2018, 1, 32; (d) H. Li, Y. Li, Z. Fang and R. L. Smith Jr, Catal. Today, 2019, 319, 84-92; (e) H. Li, Z. Fang, R. L. Smith Jr and S. Yang, Prog. Energy Combust. Sci., 2016, 55, 98-194.

5 B. J. Barr and S. B. Wallon, J. Appl. Polym. Sci., 1971, 15, 10791090.

6 B. M. Nagaraja, V. S. Kumar, V. Shasikala, A. H. Padmasri, B. Sreedhar, B. D. Raju and K. R. Rao, Catal. Commun., 2003, 4, 287-293.

7 (a) K. Yan, G. Wu, T. Lafleur and C. Jarvis, Renewable Sustainable Energy Rev., 2014, 38, 663-676; (b) T. V. Kotbagi, H. R. Gurav, A. S. Nagpure, S. V. Chilukuri and M. G. Bakker, RSC Adv., 2016, 6, 67662-67668.

8 A. Corma, S. Iborra and A. Velty, Chem. Rev., 2007, 107, 24112502.

9 M. M. Villaverde, N. M. Bertero, T. F. Garetto and A. J. Marchi, Catal. Today, 2013, 213, 87-92.

10 Y. Wang, Y. Miao, S. Li, L. Gao and G. Xiao, Mol. Catal., 2017, 436, 128-137.

11 (a) N. Date, V. L. Parola, C. Rode and M. L. Testa, Catalysts, 2018, 8, 252; (b) M. Hronec and K. Fulajtarová, Catal. Commun., 2012, 24, 100-104.

12 (a) K. Yan, J. Liao, X. Wu and X. Xie, RSC Adv., 2013, 3, 38533856; (b) S. A. Khromova, M. V. Bykova, O. A. Bulavchenko, D. Y. Ermakov, A. A. Saraev, V. V. Kaichev, R. H. Venderbosch and V. A. Yakovlev, Top. Catal., 2016, 59, 1413-1423.
13 (a) M. S. Li, Y. F. Hao, F. Cárdenas-Lizana and M. A. Keanes, Catal. Commun., 2015, 69, 119-122; (b) Q. Q. Yuan, D. M. Zhang, L. van Haandel, F. Y. Ye, T. Xue, E. J. M Hensen and Y. J. Guan, J. Mol. Catal. A: Chem., 2015, 406, 58-64; (c) J. He, H. Li, A. Riisager and S. Yang, ChemCatChem, 2018, 10, 430-438; (d) S. Srivastava, N. Solanki, P. Mohanty, K. A. Shah, J. K. Parikh and A. K. Dalai, Catal. Lett., 2015, 145, 816-823.

14 (a) D. Scholz, C. Aellig and I. Hermans, ChemSusChem, 2014, 7, 268-275; (b) V. Choudhary, S. I. Sandler and D. G. Vlachos, ACS Catal., 2012, 2, 2022-2028; (c) G. Wu, K. L. More, C. M. Johnston and P. Zelenay, Science, 2011, 332, 443-447.

15 Q. Zhang, S. S. Li, M. M. Zhu, Y. M. Liu, H. Y. He and Y. Cao, Green Chem., 2016, 18, 2507-2513.

16 (a) A. K. Roy, Adv. Organomet. Chem., 2007, 55, 1-59; (b) M. Oestreich, J. Hermeke and J. Mohr, Chem. Soc. Rev., 2015, 44, 2202-2220.

17 K. Revunova and G. I. Nikonov, Dalton Trans., 2015, 44, 840866.

18 A. Muthukumar, N. C. Mamillapalli and G. Sekar, Adv. Synth. Catal., 2016, 358, 643.

19 A. Volkov, K. P. Gustafson, C. W. Tai, O. Verho, J. E. Backvall and H. Adolfsson, Angew. Chem., Int. Ed., 2015, 54, 51225126.

20 (a) N. J. Lawrence, M. D. Drew and S. M. Bushell, J. Chem. Soc., Perkin Trans. 1, 1999, 1, 3381-3391; (b) G. Kumar, M. A. Muthukumar and G. Sekar, J. Org. Chem., 2017, 33, 4883-4890.

21 W. Xie, M. Zhao and C. Cui, Organometallics, 2013, 32, 74407444 .

22 (a) K. Fulajtárova, T. Soták, M. Hronec, I. Vávra, E. Dobročka and M. Omastová, Appl. Catal., A, 2015, 502, 78-85; (b) H. Li and R. L. Smith, Nat. Catal., 2018, 1, 176-177.

23 (a) J. M. Blackwell, K. L. Foster, V. H. Beck and W. E. Piers, J. Org. Chem., 1999, 64, 4887-4892; (b) K. Garcés, F. J. Fernández-Alvarez, V. Polo, R. Lalrempuia, J. J. PérezTorrente and L. A. Oro, ChemCatChem, 2014, 6, 1691-1697.

24 C. Bornschein, S. Werkmeister, K. Junge and M. Beller, New J. Chem., 2013, 37, 2061-2065.

25 D. Addis, S. Das, K. Junge and M. Beller, Angew. Chem., Int. Ed., 2011, 50, 6004-6011.

26 Y. Motoyama, K. Mitsui, T. Ishida and H. Nagashima, J. Am. Chem. Soc., 2005, 127, 13150-13151.

27 W. Wu, W. Zhao, C. Fang, Z. Wang, T. Yang, H. Li and S. Yang, Catal. Commun., 2018, 105, 6-10.

28 W. Zhao, W. Wu, H. Li, C. Fang, T. Yang, Z. Wang and S. Yang, Fuel, 2018, 217, 365-369.

29 M. Kira, K. Sato and H. Sakurai, J. Org. Chem., 1987, 52, 948949.

30 K. Motokura, D. Kashiwame, A. Miyaji and T. Baba, Org. Lett., 2012, 14, 2642-2645.

31 R. V. Sharma, U. Das, R. Sammynaiken and A. K. Dalai, Appl. Catal., A, 2013, 454, 127-136.

32 P. D. Vaidya and V. V. Mahajani, Ind. Eng. Chem. Res., 2003, 42, 3881-3885.

33 S. Srivastava, N. Solanki, P. Mohanty, K. A. Shah, J. K. Parikh and A. K. Dalai, Catal. Lett., 2015, 145, 816-823. 
34 M. Li, Y. Hao, F. Cárdenas-Lizana and M. A. Keane, Catal. Commun., 2015, 69, 119-122.

35 M. M. Villaverde, N. M. Bertero, T. F. Garetto and A. J. Marchi, Catal. Today, 2013, 213, 87-92.

36 W. Huang, H. Li, B. Zhu, Y. Feng, S. Wang and S. Zhang, Ultrason. Sonochem., 2007, 14, 67-74.
37 H. Pan, H. Li, H. Zhang, A. Wang, D. Jin and S. Yang, Energy Convers. Manage., 2018, 166, 534-544.

38 K. Ryoichi, T. Masatoshi and I. Yoshihiko, Tetrahedron Lett., 1998, 39, 1017-1020.

39 K. Revunova and G. I. Nikonov, Chem.-Eur. J., 2014, 20, 839845.

40 S. Rendler and M. Oestreich, Synthesis, 2005, 17, 1727-1747. 